\title{
Argentinos y ecuatorianos en Barcelona y Milán: trayectorias, dimensión urbana y capital cultural
}

\section{Luis Garzón}

Universitat Rovira i Virgili

\section{Resumen}

El presente artículo presenta una parte de las aportaciones de una tesis doctoral reciente sobre las trayectorias biográficas de inmigrantes argentinos y ecuatorianos en Barcelona (España) y Milán (Italia). Éstas están marcadas por la inserción de un determinado perfil de inmigrantes provistos de un no desdeñable volumen de capital cultural y social, en una ciudad que se encuentra inmersa en un proceso de transformación y el tránsito desde una economía de servicios a una economía industrial. El artículo pone énfasis en la dimensión urbana de la integración.

Palabras clave: argentinos, ecuatorianos, trayectoria biográfica, Barcelona, Milán.

Abstract. Argentinean and Ecuadorian immigrants in Barcelona and Milan: trajectories, urban dimension and cultural capital

This paper presents some of the findings of a doctoral thesis on biographical trajectories of Argentinean and Ecuadorian immigrants in Barcelona (Spain) and Milano (Italy). These trajectories are characterized by the insertion of a given profile of immigrants characterized by a high volume of cultural and social capital in a city which is immersed in a process of transformation and in the transit from a service economy to an industrial economy. The paper emphasizes precisely the urban dimensions of integration.

Key words: Argentinean, Ecuadorian, biographical trajectories, Barcelona, Milano.

El presente trabajo se inscribe en el contexto de una tesis doctoral recientemente concluida sobre las trayectorias biográficas de la inmigración argentina y ecuatoriana en las ciudades de Barcelona (España) y Milán (Italia). Ambas ciudades han experimentado, en los últimos años, procesos de transformación urbana y terciarización.

Argentina y Ecuador poseen vínculos con España e Italia que se remontan a muy antiguo. Argentina, en particular, tiene una histórica relación con España e Italia, países con los cuales se establecieron acuerdos a finales del siglo XIX 
para el reconocimiento de la doble ciudadanía (Jensen, 2002). Estos acuerdos entre el país de origen y el país de recepción son importantes, en tanto que permiten acceder a los argentinos a los beneficios de la integración política, puesto que adquieren la ciudadanía española e italiana con mayor rapidez que otros grupos de inmigrantes.

El número de inmigrantes argentinos y ecuatorianos que se dirigen a Barcelona y a Milán ha aumentado rápidamente en el último lustro. Uno de los factores que mayor peso ha tenido en este aumento ha sido la crisis que ha golpeado América Latina. La principal manifestación de la crisis en Argentina ha sido el "corralito", es decir, el cierre de los bancos. Ecuador, por otro lado, ya había sido país de emigración durante gran parte del siglo XX, en especial dirigida a los Estados Unidos (Pedone, 2002).

En el contexto de Barcelona como ciudad receptora de inmigrantes, cabe destacar la gran importancia que reviste la inmigración cualificada, es decir, la inmigración que ha realizado estudios superiores en el país de origen y que llega a Barcelona atraída por las mayores posibilidades de desarrollo profesional y posibilidades culturales ofrecidas por la ciudad con relación a otros lugares de España o de Cataluña.

La inmigración argentina que está inmigrando a Barcelona pertenece a los estratos más afectados por dicha crisis económica: las clases medias. Concretamente, un gran número de los inmigrantes argentinos a Barcelona y Milán se insertan en el contexto de la "fuga de cerebros» (Pellegrino, 2000) que están experimentando, en los últimos años, muchos países de América Latina, debido a la crisis económica del área.

Ecuador, por otra parte, ha tenido una historia y una evolución política y económica convulsa, lo que contribuye a conformar un perfil socioeconómico y cultural de su población y, por ende, de su emigración, notablemente diferente. A continuación, nos detenemos brevemente en una variable, que constituye un elemento explicativo central de las razones por las cuales Barcelona resulta más atractiva para los colectivos de inmigrantes de los que nos estamos ocupando: el capital cultural. Los niveles de estudio, que, en el modelo de Bourdieu (1999), corresponderían aproximadamente a lo que este autor denomina «capital cultural adquirido".

El propósito de nuestra investigación ha sido, pues, hacer visible la trayectoria biográfica de un sujeto que pasa de ser emigrante a inmigrante. Aquello que lleva a la persona a convertirse en emigrante es el resultado de una determinada posición en las jerarquías de poder simbólico que se traduce en un determinado volumen y estructura del capital. El posicionamiento conduce a la persona a emigrar donde su trayectoria ya no está tan sólo marcada por el peso de la estructura y el volumen del capital en origen, sino también por el acceso o la falta de acceso a la pertenencia nacional, también denominada «capital nacional» (Hage, 2000), que se dispensa en las instancias dominantes en el campo político de la sociedad de acogida.

La metodología adoptada para realizar nuestro trabajo de campo y llevar a cabo la recogida de información ha sido la entrevista biográfica en profundidad. 
Esta técnica permite una captación de la experiencia biográfica del inmigrante desde su socialización hasta su experiencia educativa y laboral en origen, para finalizar en la experiencia en el lugar de acogida (Bourdieu, 1999). Según Alonso (1999), las entrevistas en profundidad en una investigación que utilice la metodología cualitativa serán más útiles cuanto más representativo de un perfil o de un arquetipo determinado sea el entrevistado.

Sobre las dos ciudades donde se ha realizado el trabajo de campo, hemos encontrado valoraciones contrapuestas por parte de los inmigrantes. Una parte destacada de los entrevistados, comentaba que lo único que conocía sobre Barcelona antes de llegar era que se trataba de una ciudad cosmopolita, donde las actividades culturales eran atractivas. Estos comentarios los hacían más a menudo los inmigrantes argentinos, pero cabe insistir en que ello se debe al hecho de que los inmigrantes procedentes de este país son personas cuya estructura y volumen del capital privilegia los factores culturales.

Los argentinos gozan de un capital incorporado y de unos conocimientos que les permiten aprovechar en mayor medida las oportunidades ofrecidas por la ciudad. La valoración de la cultura no tiene sólo que ver con el capital cultural acumulado (títulos escolares), sino también con el ya incorporado en la socialización en familias que daban importancia a éste, a través del interés por productos culturales.

Uno de los colectivos de argentinos entre los cuales aumenta el atractivo de emigrar a Barcelona son los graduados universitarios de promociones recientes, que son los más afectados por la crisis del mercado laboral que ha seguido a la debacle económica del 2000. Las universidades de Barcelona han atraído a una cantidad creciente de estudiantes de postgrado procedentes de América Latina, que, ante la devaluación de los diplomas académicos en el país de origen, se trasladan a la ciudad para ampliar estudios.

Respecto a los ecuatorianos, nuestras entrevistas nos permiten constatar que consideran la ciudad como lugar de trabajo, un lugar en el cual ganar dinero, acumulando capital económico para financiar los proyectos en origen. Barcelona se convierte, de esta manera, en la llave de la conversión del capital económico en otros tipos de capital. La pauta habitual en las trayectorias biográficas de las mujeres ecuatorianas, según emerge en las entrevistas realizadas, es haber iniciado estudios secundarios en Ecuador, que tuvieron que dejar al casarse y quedar embarazadas. Es muy frecuente que el embarazo suponga una ruptura decisiva en una trayectoria, que, antes de este hecho, podía ser considerada de movilidad social ascendente.

La principal razón aducida para emigrar a Barcelona entre los ecuatorianos está vinculada al uso que hacen los entrevistados del capital social, es decir, de las redes de las que disponen. El capital social, como Ambrosini (1999) ha señalado, puede tener efectos ambivalentes, ya que los información del mercado de trabajo, pero a la vez limitando las posibles opciones de los inmigrantes. Los entrevistados han afirmado, en repetidas ocasiones, que sus contactos, incluso entre personas que conocían ya en Ecuador, les habían engañado o proporcionado información que más tarde se había revelado errónea. En el 
caso de los ecuatorianos residentes en España, Claudia Pedone (2002) ha estudiado la importancia que para ellos reviste la red como mecanismo para su integración.

Existe, sin embargo, otro grupo de ecuatorianos para los que el capital social que les ha llevado a emigrar a Milán no es endógeno, sino capital social exógeno. Se trata de personas que han trabajado en Ecuador en posiciones de responsabilidad en multinacionales y, a través de su empleo en dichas empresas, disponían de contactos con personas europeas, a menudo en varios países, y aprovecharon los contactos para ir tejiendo una red de conocidos en Europa. Un aspecto recurrente en las entrevistas es la dificultad de regularizar la situación en Milán. Ante la ausencia de vías de entrada «regulares», los inmigrantes deben recurrir a la legalización por matrimonio.

Por otro lado, algo que ha sido señalado repetidas veces en las entrevistas realizadas en Milán, es que esta ciudad es vista como un lugar «viejo». Es decir, en oposición a la modernidad y a la apertura que se percibe en Barcelona, lo más característico de Milán es que es un lugar antiguo, en el cual parecen darse pocos elementos urbanísticos atractivos. Frente a la Barcelona «bonita», Milán es vista como un lugar «viejo».

Barcelona es percibida, por los inmigrantes procedentes de Argentina y Ecuador, como un lugar acogedor y en el cual es posible desarrollar actividades y acceder a oportunidades que en el país de origen quedan fuera de su alcance. Vivir en Barcelona es vivir en una ciudad donde se ofrecen espacios para el desarrollo personal y posibilidades para convertir el capital acumulado en origen en otros tipos de capital.

La ciudad de Milán, en principio, aparece como menos acogedora para los inmigrantes. No posee apenas ninguno de los atractivos de los que sí goza Barcelona y es percibida como lugar antiguo. El único rasgo positivo que tiene Milán es que es vista como una ciudad «industrial», rasgo que, sin embargo, contrasta con el hecho de que la mayor parte de los inmigrantes ecuatorianos trabajan en el sector servicios.

Para concluir, señalamos que tanto Barcelona como Milán ofrecen oportunidades y perspectivas laborales a los inmigrantes argentinos y ecuatorianos. Sin embargo, Barcelona parece ofrecer mayores posibilidades para el desarrollo de proyectos individuales, mientras que en Milán se dificulta la posibilidad de desarrollar proyectos individualizados.

\section{Bibliografia}

Ambrosini, M. (1999). Utili invasori. Milán: Franco Angeli.

Bourdieu, P. (1999). Meditaciones pascalianas. Barcelona: Anagrama.

DeBENE, O. (2000). America latina en el siglo XX. Madrid: Síntesis.

HaGe, G. (2000). White nation. Nueva York: Routledge.

Jensen, S. (2001). Exilio politico y emigración económica en Cataluña (1976-1996).

Tesis doctoral presentada en el Departament d'Història de la Universitat Autònoma de Barcelona. 
MartinotTi, G. (1994). Metropoli. Bolonia: Il Mulino.

Pedone, C. (2002). Tu siempre jalas a los tuyos. Tesis doctoral presentada en el Departament de Geografia de la Universitat Autònoma de Barcelona.

Pellegrino, A. (2002). «Skilled Labour Migration from developing countries: Study on Argentina and Uruguay». En: International Migrations Paper, Ginebra: ILO. Solé, C. (1997a). Modernizacion: un análisis sociológico. Barcelona: Anthropos. 